\title{
Helium Bombardment Leak Testing of the Closure Disk Weld for MC2949, MC3004, and MC3095 Pyrotechnic Devices
}

\author{
Walter A. Dudley
}

Issued: March 31, 1980

This report was prepared as an account of work sponsored by an agency of the United States Government. Neither the United States Government nor any agency thereof, nor any of their employees, makes any warranty, express or implied, or assumes any legal liability or responsibility for the accuracy, completeness, or usefulness of any information, apparatus, product, or process disclosed, or represents that its use would not infringe privately owned rights. Reference herein to any specific commercial product, process, or service by trade name, trademark, manufacturer, or otherwise does not necessarily constitute or imply its endorsement, recommendation, or favoring by the United States Government or any agency thereof. The views and opinions of authors expressed herein do not necessarily state or reflect those of the United States Government or any agency thereof.

MOUND FACILITY

Miamsburg, 0 ho 45342

operated by

MONSANTO RESEARCH CORPORATION

a subsidiary of Monsanto Company

for the

U. S. DEPARTMENT OF ENERGY 


\section{DISCLAIMER}

This report was prepared as an account of work sponsored by an agency of the United States Government. Neither the United States Government nor any agency Thereof, nor any of their employees, makes any warranty, express or implied, or assumes any legal liability or responsibility for the accuracy, completeness, or usefulness of any information, apparatus, product, or process disclosed, or represents that its use would not infringe privately owned rights. Reference herein to any specific commercial product, process, or service by trade name, trademark, manufacturer, or otherwise does not necessarily constitute or imply its endorsement, recommendation, or favoring by the United States Government or any agency thereof. The views and opinions of authors expressed herein do not necessarily state or reflect those of the United States Government or any agency thereof. 


\section{DISCLAIMER}

Portions of this document may be illegible in electronic image products. Images are produced from the best available original document. 


\section{Contents}

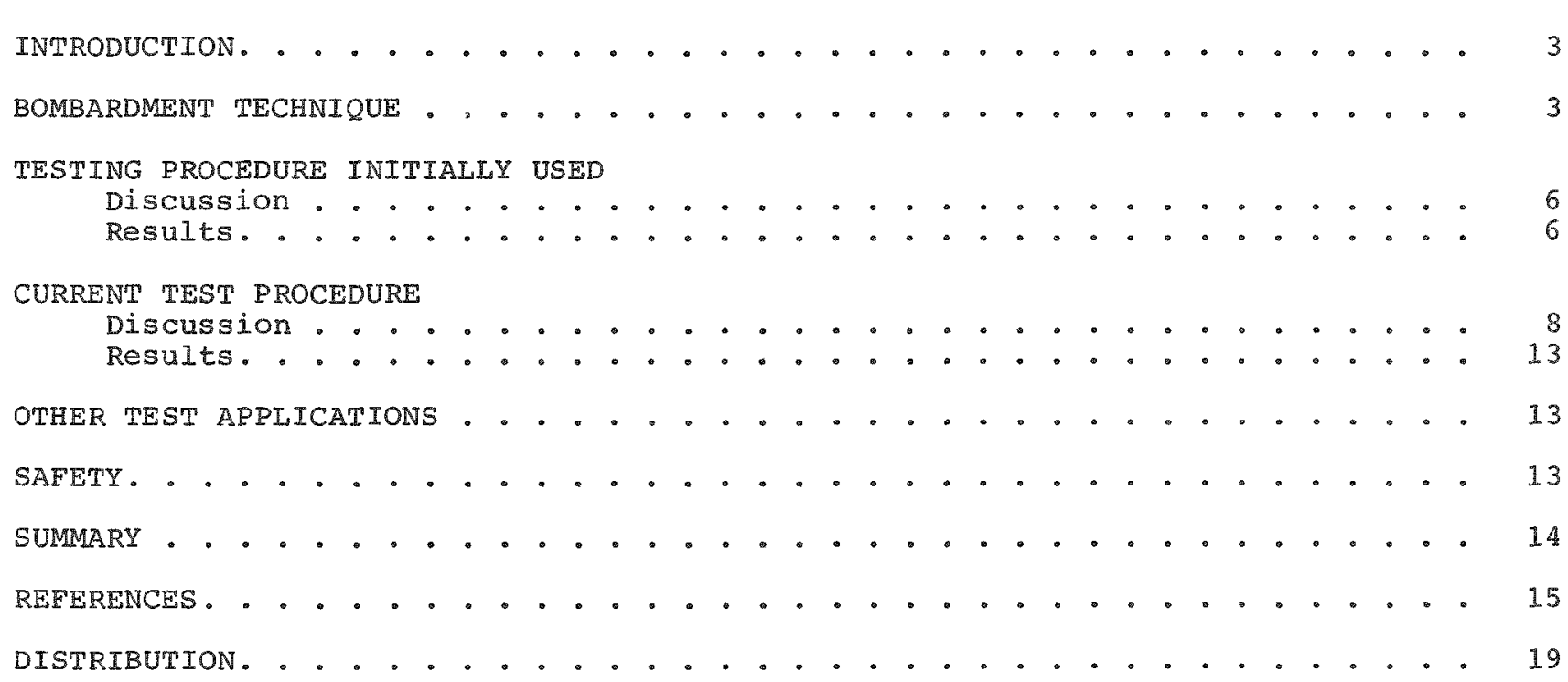




\section{Abstract}

A helium bombardment leak test procedure was developed to determine the leak level of the closure disk weld performed on three nearly identical pyrotechnic actuators. The inspection procedure is capable of leak testing any of the three product types at a rate better than 120 units per 8-hr work shift.

Testing is performed on a $100 \%$ sample plan and employs a go/no-go bombardment leak rate acceptance specification of $3 \times 10^{-9}$ atm$\mathrm{cm}^{3}-\mathrm{sec}^{-1}$. In addition to the current test procedure and results, this report includes a description of procedure and results associated with the test as initially performed. Other applications of the current technique are also listed.

\section{Introduction}

The long-term service life required of the MC2949, MC3004, and MC3095 pyrotechnic actuators necessitates that they be impervious to moisture transfer, that is leak tight to better than $1 \times 10^{-5} \mathrm{~atm}^{-\mathrm{cm}^{3}}$ $\sec ^{-1}$. To ensure that these products meet this leakage requirement, a helium bombardment leak test technique was developed to determine seal quality of the closure disk weld for each individual unit. The practical lower linit of detection of the test procedure developed is theoretically equivalent to that provided by a leakage conductance of $I \times 10^{-7}$ $\mathrm{cm}^{3}-\mathrm{sec}^{-1}$. An illustration showing construction of an MC3004 unit and representative of the design of the other two product types is shown in Figure 1. A photograwh of the final assembly of all three products is shown in Figure 2 .

Initially, because of the extremely small free volume of $0.030 \mathrm{~cm}^{3}$ common to all three products, it was thought that a gross leak would not be detected by bornbardment testing alone. Therefore, a helium-alcohol-bubble technique was separately performed to test for gross leaks. It has since been established, however, that the bombardment technique does provide full range leak detection, and, therefore, the "bubble" inspection technique was dropped as a test requirement.

\section{Bombardment technique}

Helium bombardment testing consists of two distinct operational steps. First the item to be leak tested is "charged", that is, backfilled with helium using a pressurization chamber. After "charging" is completed, the test item is then coupled to a mass spectrometer, and the rate of helium discharge is measured.

Interpretation of the measured leak rate can generally be determined using Equation 1.

$$
L_{M}=P\left(1-e^{-\lambda_{1}}\right)\left(e^{-\lambda_{1}}\right) C
$$

where $L_{M}=$ measured leak rate

$$
\left(\mathrm{atm}-\mathrm{cm}^{3}-\mathrm{sec}^{-1}\right. \text { ) }
$$

$\mathrm{P}=$ helium charging pressure (atm)

$\lambda=c / v\left(\sec ^{-1}\right)$

$V=$ iree volume of test item $\left(\mathrm{cm}^{3}\right)$ 


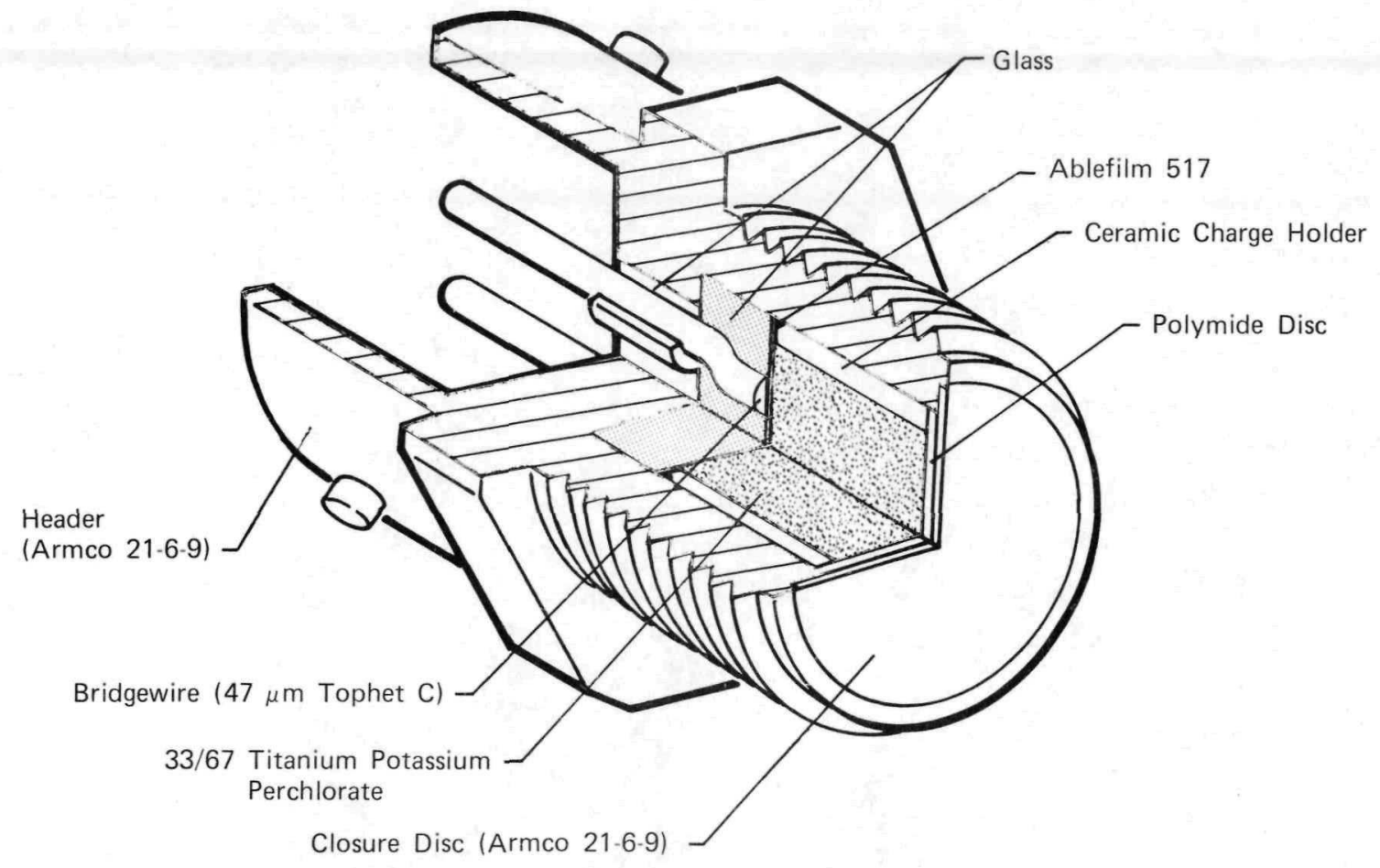

FIGURE 1 - Assembly view showing design and construction of MC 3004 pyrotechnic actuator.

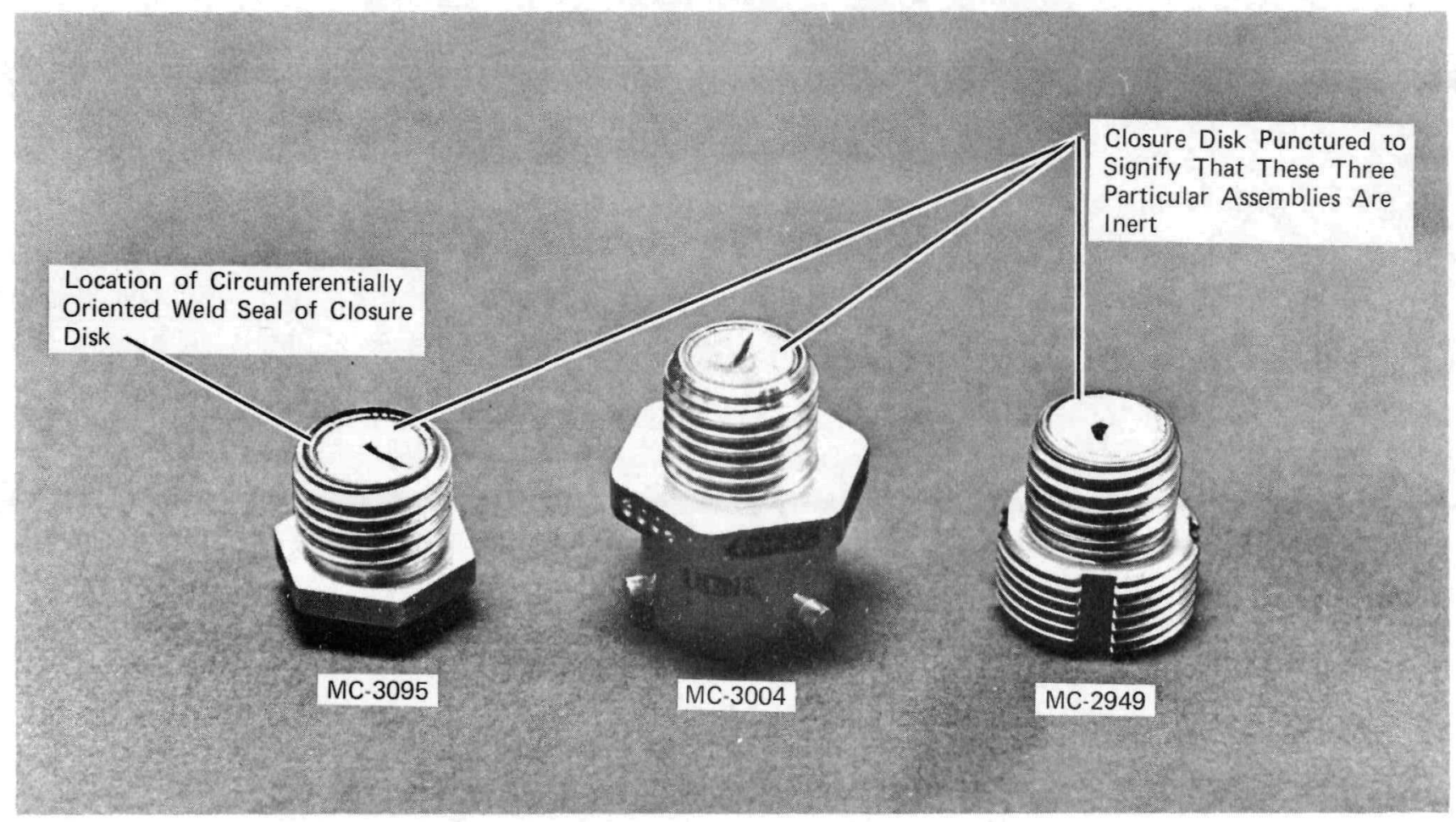

FIGURE 2 - Final assembly of all three products. 


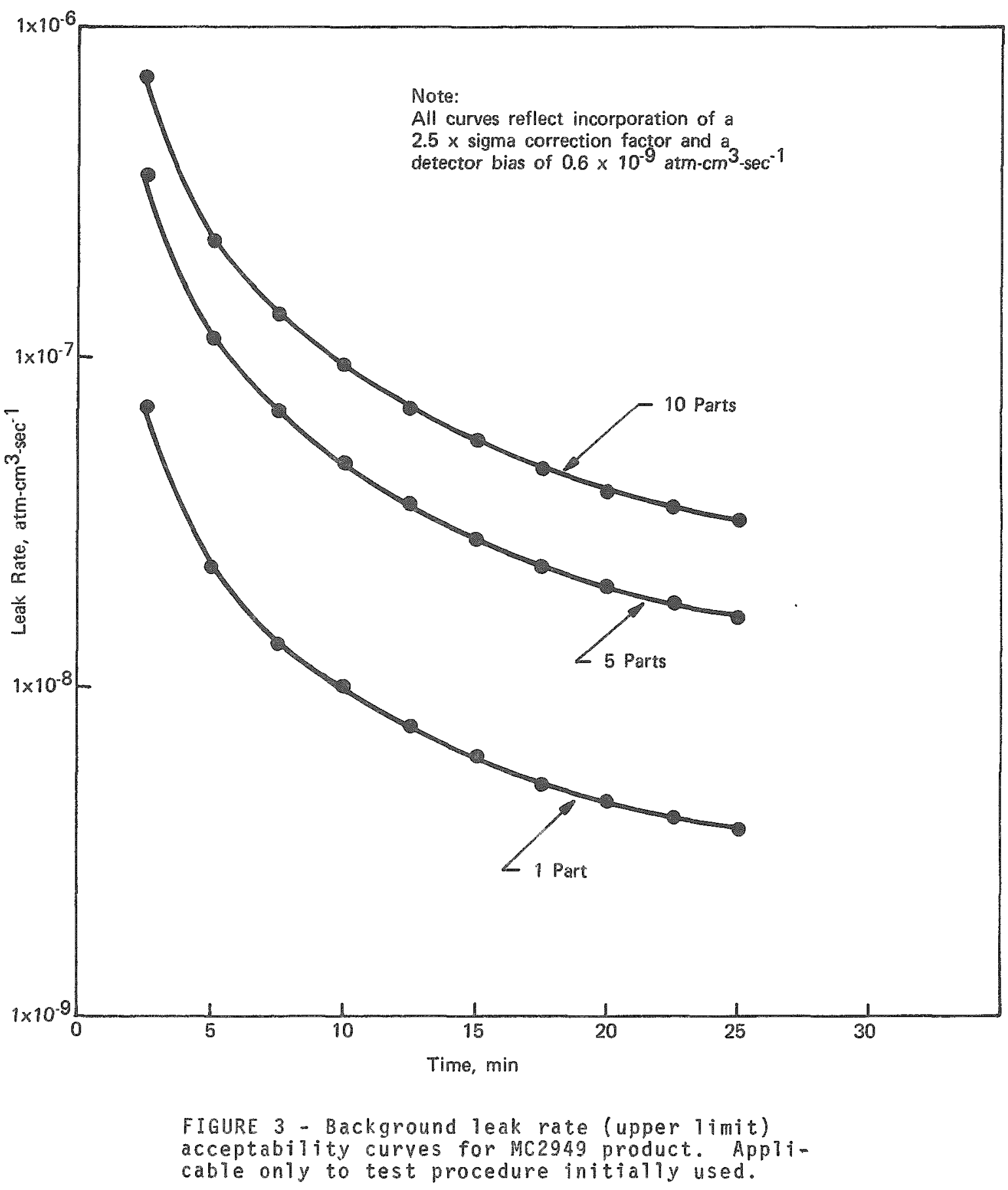




$$
\begin{aligned}
\mathrm{C}= & \text { leakage conductance } \\
& \left(\mathrm{cm}^{3}-\text { sec }^{-1}\right) \\
\tau_{1}= & \text { charging time (sec) } \\
\tau_{2}= & \text { elapsed time from start of } \\
& \text { discharge (sec) }
\end{aligned}
$$

A simplified explanation of the application of Equation 1 is as follows: The $\left(1-e^{-\lambda \tau_{1}}\right)$ term can be viewed as representing the percentage of backfill accomplished relative to an elapsed charging time of $\tau_{1}$ seconds. The $e^{\lambda \tau_{2}}$ term can be viewed as the percentage of backfill remaining after an elapsed discharge time of $\tau_{2}$ seconds. other technical literature concerning applied use of the bombardment technique is given in References 1 through 3 .

\section{Testing procedure initially used}

\section{Discussion}

In the test procedure initially employed, 10 parts were measured simultaneously. Data were collected by continuous monitoring of the discharge leak rate of all 10 units until a definite trend of the leak rate as a function of time was established via a plot. The data were assessed for evidence of leakers by comparing the plot against an appropriate background leak rate curve.

Individual leakers were identified by subdividing the test group into small sublots and repeating the measurement test procedure as applicable.

Background leak rate curves established for groups of 10,5 , and 1 units are shown for the three product types in Figures 3 through 5, respectively. Figure 6 is a photograph of the leak test station. The basis for the different background leak rates is that each of the nearly identical product types have slightly different helium absorption characteristics and, therefore, outgas differently.

In addition, and prior to bombardment testing, an alcohol-bubble test was separately performed to detect gross leakers. The bubble test was, at the time, considered necessary since calculations using Equation " 1 indicated that units with a conductance much larger than $1 \times 10^{-4} \mathrm{~cm}^{3} / \mathrm{sec}$ would not be detected by the bombardment technique. The resultant bombardment theoretical leak rate curves obtained from Equation 1 for various conductance values are shown in Figure 7 .

Equipment and procedural specifics for both the bombardment and bubble techniques as initially employed are given in Table 1.

\section{Results}

The inspection results obtained for testing MC2949, MC3004, and MC3095 weld seals with the inspection technique used initially are sumarized in Table 2. Typical bombarament leak rate curves obtained for longterm monitoring of individual units considered as reject for each respective product are shown in Figure 8 . Similar data for a "suspect" leak condition in the MC2949 product are shown in Figure 9.

Two separate studies were performed to verify interpretation associated with the bombardment test results given in pable 2 . From these studies, the following conclusions were drawn:

1. The "suspect condition" (noncharacteristic leak test datal is attributed to detection of virtual leakers (pseudo leakers -- trapped surface helium)。

2. The source of the virtual leakage, in particular for the MC2949 product, 


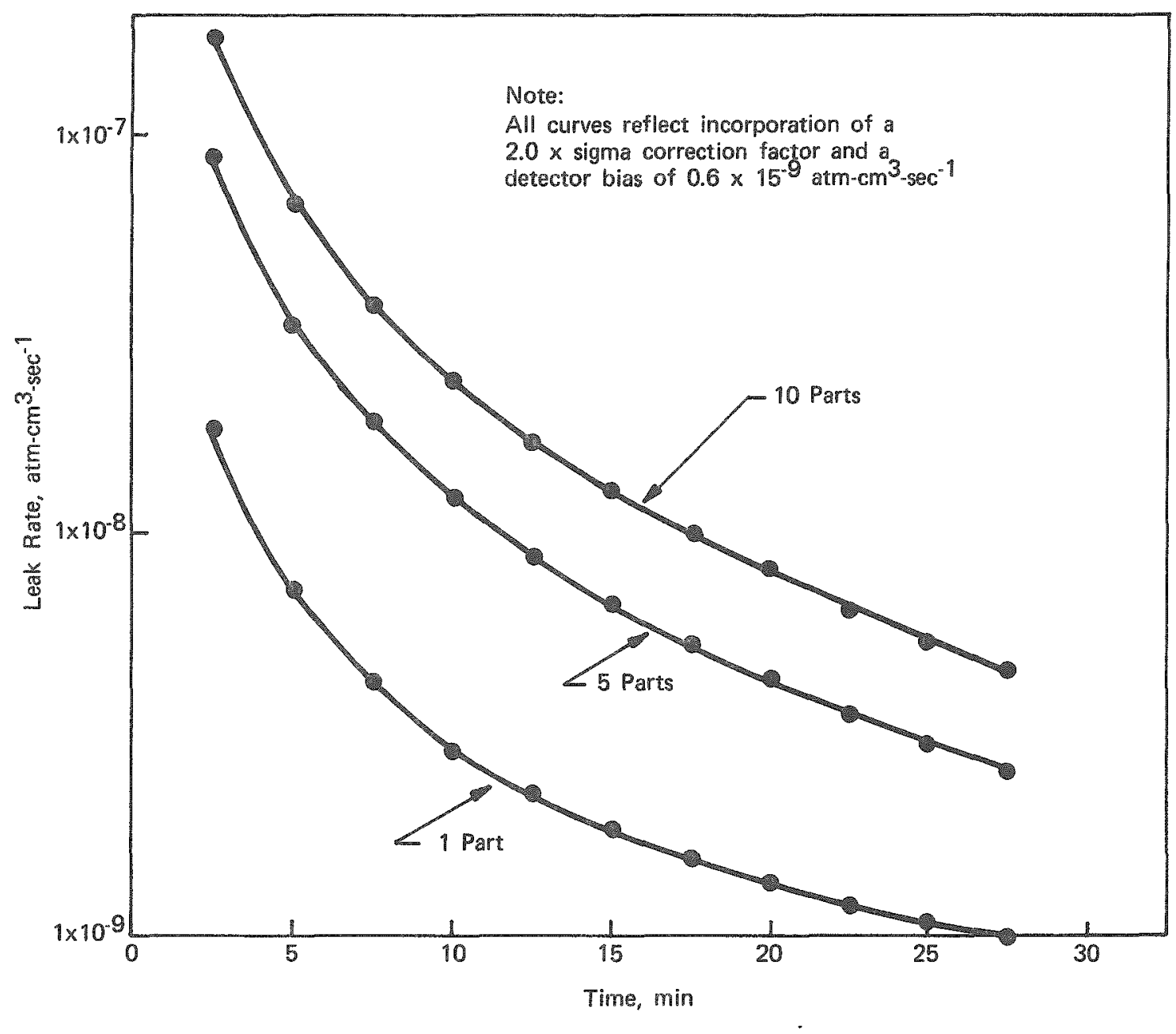

FIGURE 4 - Background leak rate (upper Iimit) acceptable curves for MC3004 product. Applicable only to test procedure initially used.

is the random occurrence of cavities in the outer surface interface of the glass-tometal seal.

3. Units considered as reject are definite leakers, which, in general, are gross leakers and not detected with the alcohol-bubble test.

4. The unexpected capability demonstrated by the bombardment technique to detect gross leaks is attributed to outgassing of $a b-$ sorbed helium, primarily from the charge holder component of each respective assembly. other components that contribute to outgassing are the pyrotechnic pressings themselves and the internal ceramic surfaces. The data in Figure 8 , which shows the total outgassing observed from all these sources for each product type, are typical of a gross weld leak.

5. The detection capability of the alcohol-bubble test technique in these test applications is estimated, relative to differential testing at $1 \mathrm{~atm}$, to range from $1 \times 10^{-3}$ to $1 \times 10^{-4} \mathrm{~atm}-\mathrm{cm}^{3}-\mathrm{sec}^{-1}$. 


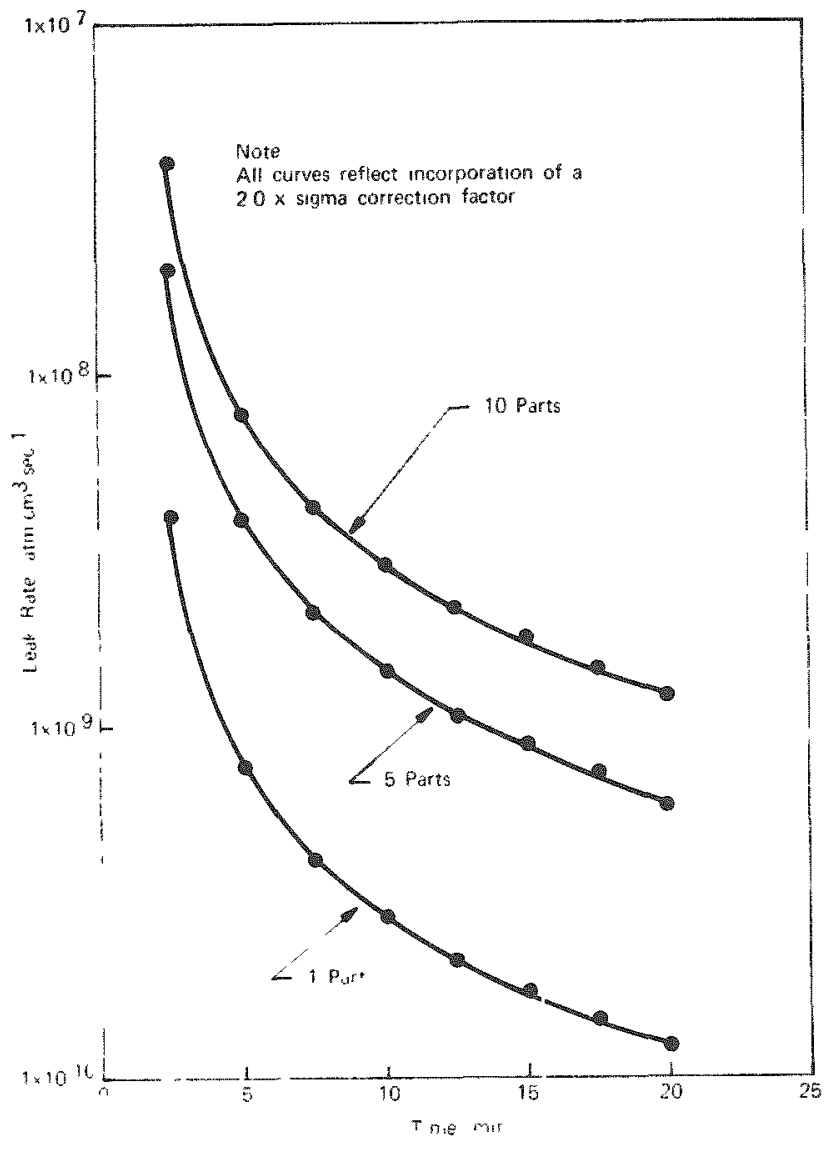

FIGURE 5 - Background leak rate (upper limit) acceptability curves for MC 3095 product. Applicable only to test procedure initially used.

6. There were very few leakers in the range from $1 \times 10^{-4}$ to $1 \times 10^{-7}$ $a t m-\mathrm{cm}^{3}-\sec ^{-1}$.

\section{Current test procedure}

\section{Discussion}

The current test procedure is essentially a streamined version of that initially employed. Streamlining consisted primarily of incorporating the following generalized revisions:

1. During the measurement phase of testing, the units comprising the test group are measured individually.

2. The test group size was increased to a maximum of 25 units.

3. Only the welded end of the unit under test is coupled to the leak detector.

4. Only a single bombardment leak rate measurement is obtained for each unit tested.

5. Assessment of the leak rate obtained for the item under test is determined against a single bombardment leak rate specification.

6. Alcohol-bubble testing was deleted.

Because the header component for the various products is $100 \%$ independently tested for leakage prior to use, no product integrity is forfeited by adoption of Revision 3 .

The overall advantages of the incorporated procedural revisions are as follows:

1. Test efficiency is essentially doubled and will permit testing of a minimum of 120 units per 8-hr work shift.

2. Separate testing for gross leakers has been eliminated. 


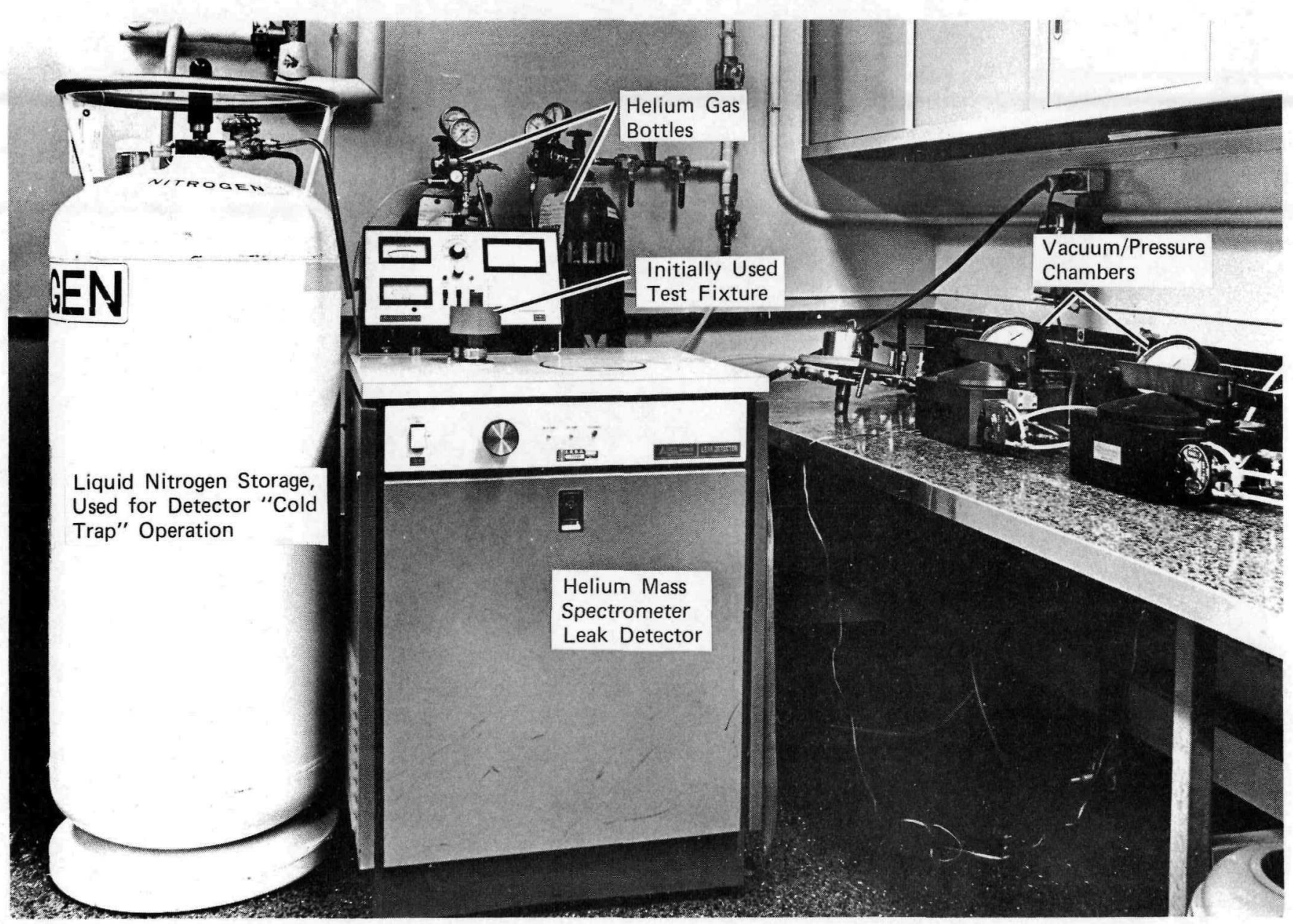

FIGURE 6 - Leak test station.

3. Confusing the test results of virtual leakers with real leakers has been eliminated.

4. Acceptability of the respective product is determined against a common leak test specification.

5. A common background leak rate is obtained for all three product types (see Figures 2 and 11). Because of the nearly identical design of all three products, the common background for weld end testing is to be expected.
A sketch of the test fixture currently used in the measurement phase of testing is shown in Figure 10. Equipment and test procedures used in the current test are given in Table 3. The current background curve and the leak rate specification are illustrated in Figure 11.

The basis for the current leak test specification $\left(3 \times 10^{-9} \mathrm{~atm}-\mathrm{Cm}^{3}-\mathrm{sec}^{-1}\right)$ is twofold. First, the specification (see Figure 11) corresponds theoretically to what would essentially be observed in these test applications for continuous monitoring of a leaker with a conductance of $1 \times 10^{-7} \mathrm{~cm}^{3}-\mathrm{sec}^{-1}$. Secondly, the 


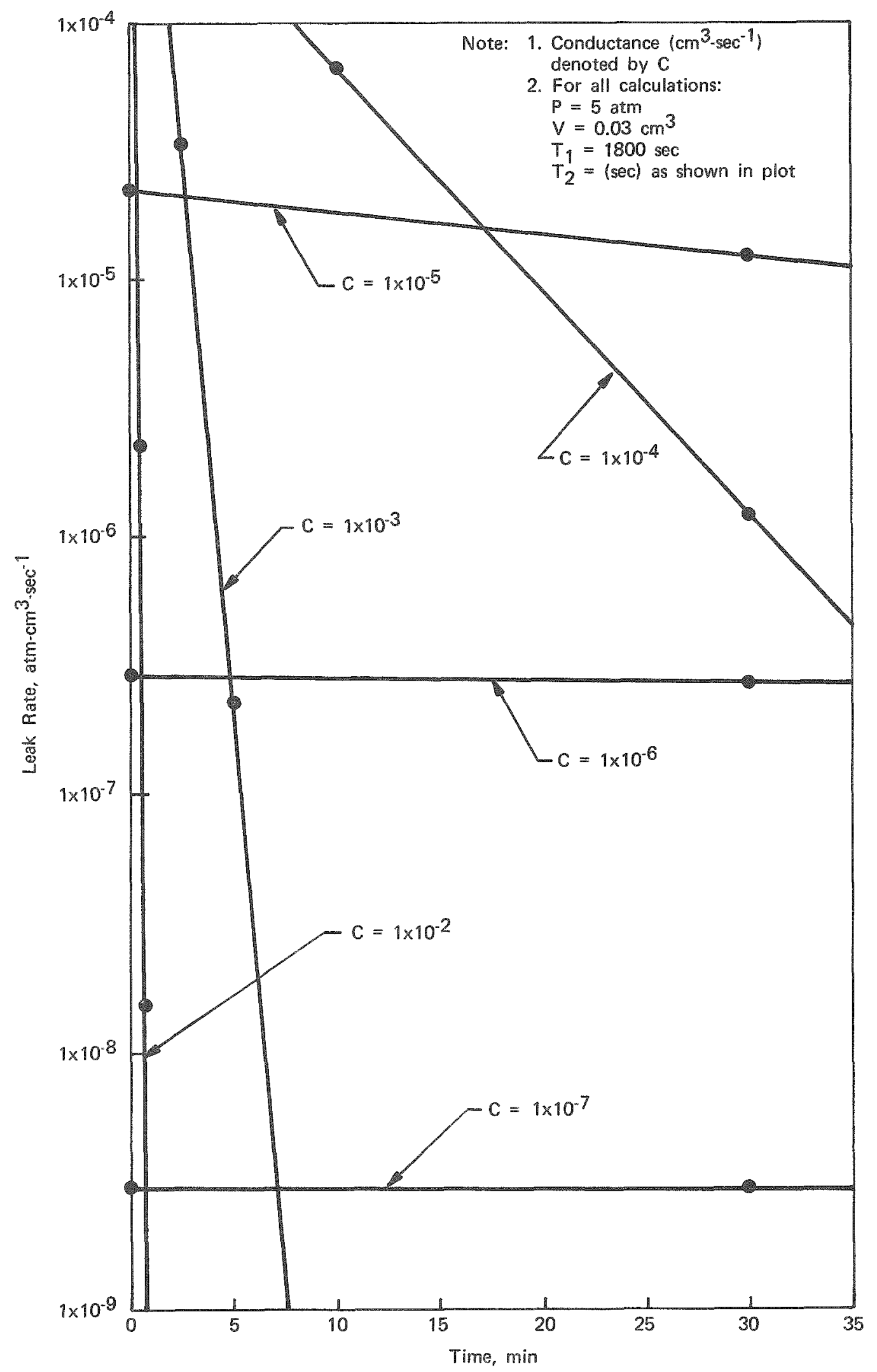

FIGURE 7 - Resultant bombardment (discharge) leak rate curves obtained from Equation 1 for various values of leakage conductance. 
1. Equipment
a) Leak Detector: Airco Temescal, Model LC40 or equivalent
b) Test Fixture: Fig. 6, Engr. Dwg. AYC 770250
c) Vac/pressure chamber: Fig. 6

2. Sample Preparation
a) Quantity: Ten or less units per test cycle
b) Pull Down: Minimum of 20 min of vacuum $27 \mathrm{in}$. Hg or better
c) Helium Exposure: Minimum of $30 \mathrm{~min}$ (not exceeding $35 \mathrm{~min}$ ) using certi- fied Grade A helium at 5 atmos

3. Sample Cleanup
a) Dry compressed air at low pressure (not exceeding $60 \mathrm{lb} / \mathrm{ft}^{2}$ )

4. Sample Measurement

a) Technique: Continuous monitoring approach, coupled with random manual plotting of measured leak rate as a function of time

b) Data Accessment: Comparison to acceptability curve

c) Identification of Leakers: Subdividing test group and repeating sample measurement steps $A \& B$
1. Equipment
a) Alcohol: Isopropy 1 (bonded stores certified)
b) Disk: Crystallizing type or equivalent

2. Sample Preparation
a) Quantity: 30 items or less per test cycle
b) Pull Down: Minimum of $10 \mathrm{~min}$ of vacuum ( $27 \mathrm{in.} \mathrm{Hg}$ or better)
c) Helium Exposure: Minimum of 10 min using certified Grade $A$ helium at 5 atmos

3. Sample Cleanup

a) None required

4. Sample Accessment

a) Technique: Plunge bombarded units directly into Alcohol

b) Identification of leakers: Visual detection of bubbles escaping from wela region of immersed unit

\footnotetext{
Table 2 - SUMMARY OF RESULTS OBTAINED FROM TEST PROCEDURE USED INITIALLY

\begin{tabular}{|c|c|c|c|}
\hline \multirow[b]{2}{*}{ Product } & \multirow[b]{2}{*}{$\begin{array}{c}\text { No. of Units } \\
\text { Tested } \\
\end{array}$} & \multicolumn{2}{|c|}{ Rejects } \\
\hline & & $\begin{array}{l}\text { Alcohol-bubble } \\
\text { Approach }\end{array}$ & $\begin{array}{l}\text { Bombardment } \\
\text { Approach }\end{array}$ \\
\hline MC2949 & 875 & 25 & 198 \\
\hline MC3004 & 233 & 2 & 12 \\
\hline MC 3095 & 266 & 5 & 3 \\
\hline
\end{tabular}

$\frac{\frac{\text { Suspect condition }}{\text { Bombardment }}}{\text { Approach }}$

aprocedure effectivity, April 1977 through January 1978.

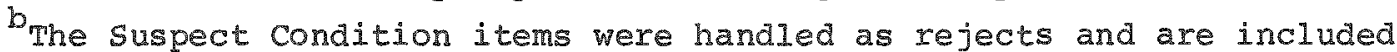
in the Listed Reject Data.
} 


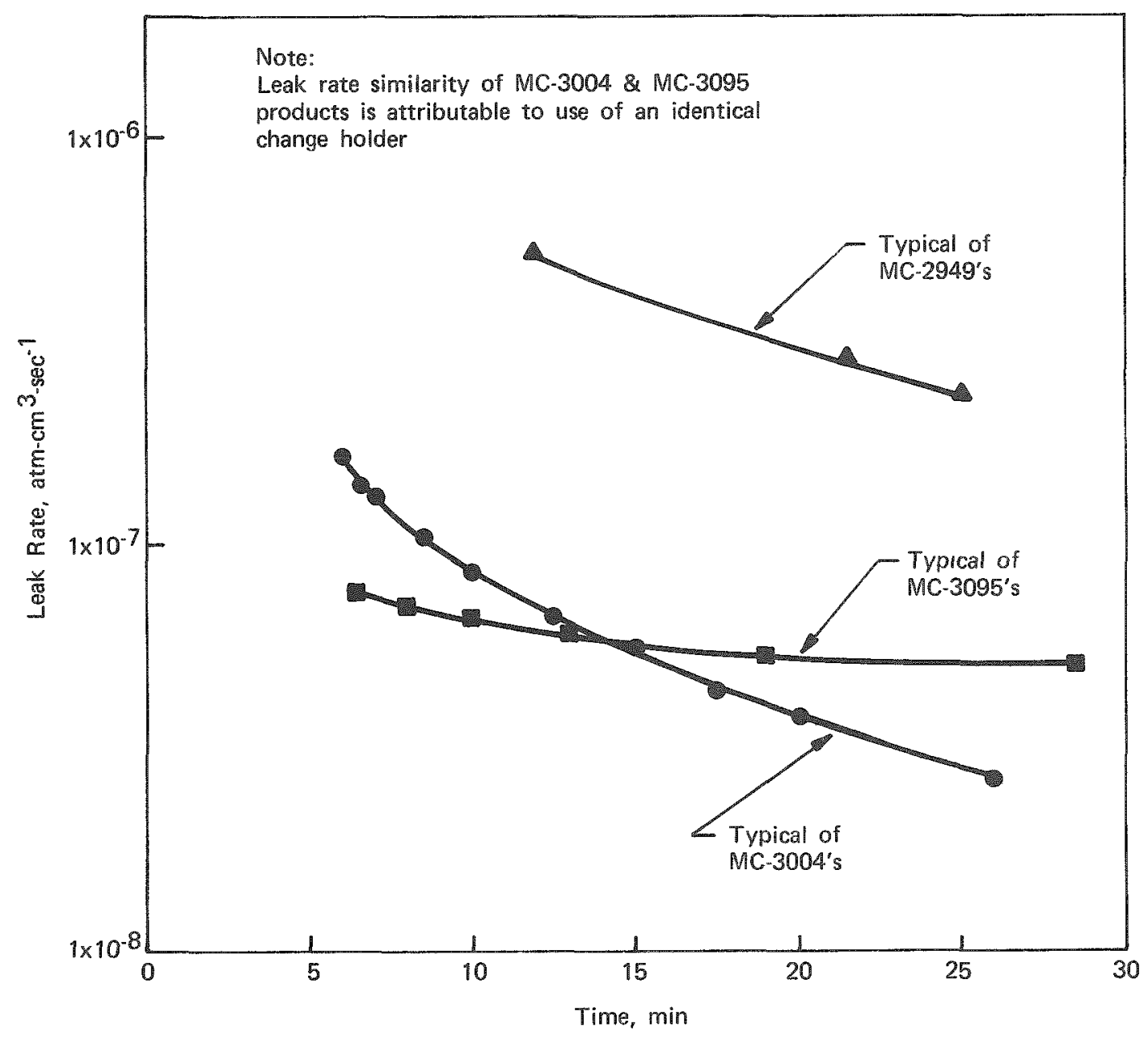

FIGURE 8 - Typical leak rate curves obtained by continuous monitoring of detected gross leakers. 


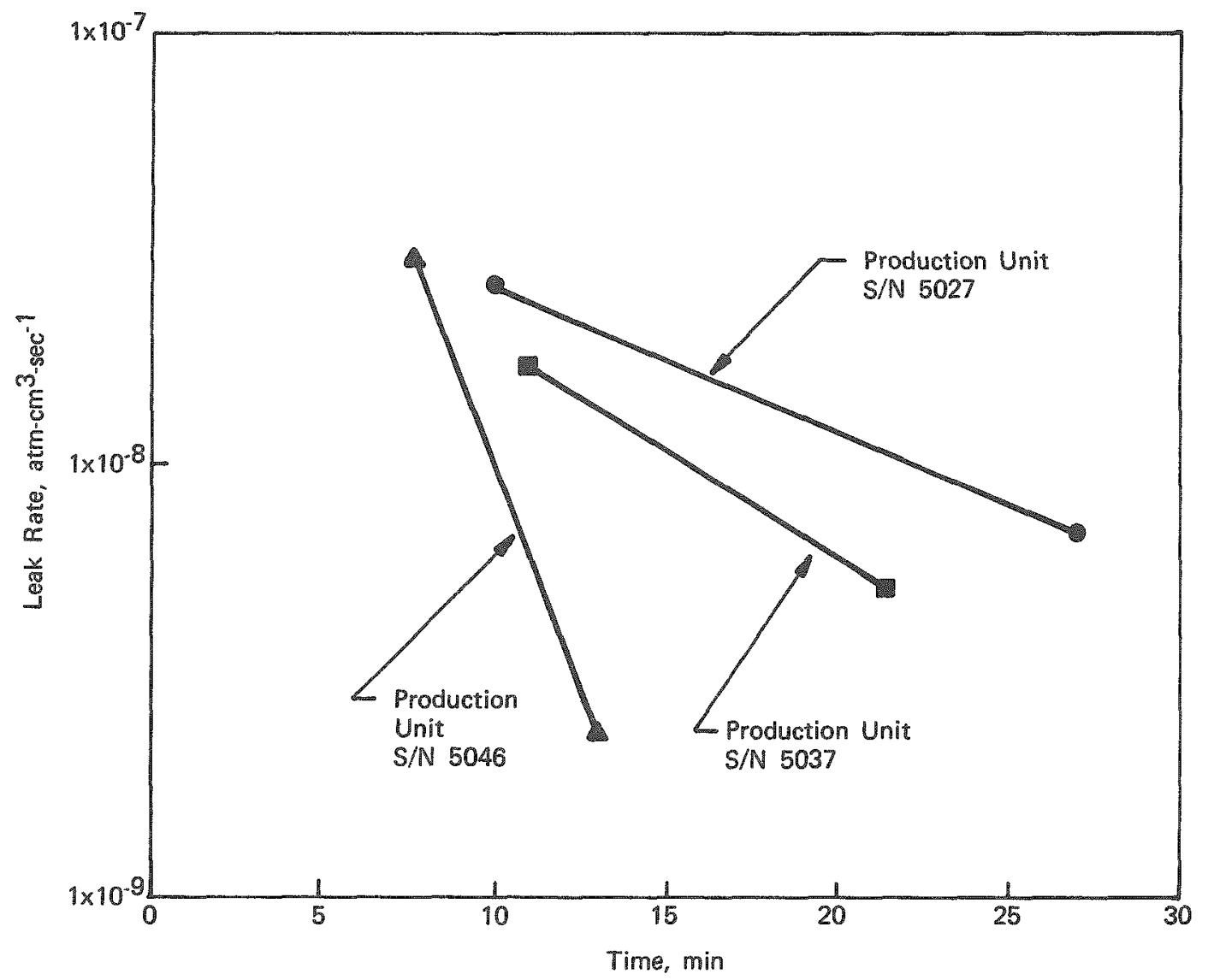

FIGURE 9 - MC2949 suspect (virtual) leakers. Curves shown are typical of what is obtained for continued monitoring of this detected leak condition.

specified leak rate is easily distinguished from the common background throughout the entire test period of $30 \mathrm{~min}$.

\section{Results}

A summary of the inspection cesults obtained to date with current test procedure is given in Table 4. A comparison of the data in Tables 2 and 4 shows that the reject rate for the MC2949 product was significantly reduced (22.8\%). This improvement is a result of having corrected a welding compatibility problem with MC2949 materials and the ability to distinguish between actual and virtual leakers with the current leak test procedure. As expected, no significant change occurred in the reject rate of the other two product types, because there were no real production problems.

\section{Other test applications}

The bombardment leak test procedure as both initially and currently performed provides occasional support for several other programs. These other programs and the purpose of testing are listed in Table 5.

\section{Safety}

The hazards associated with handling pyrotechnic powders are considerably reduced when the material has been pressed to high 


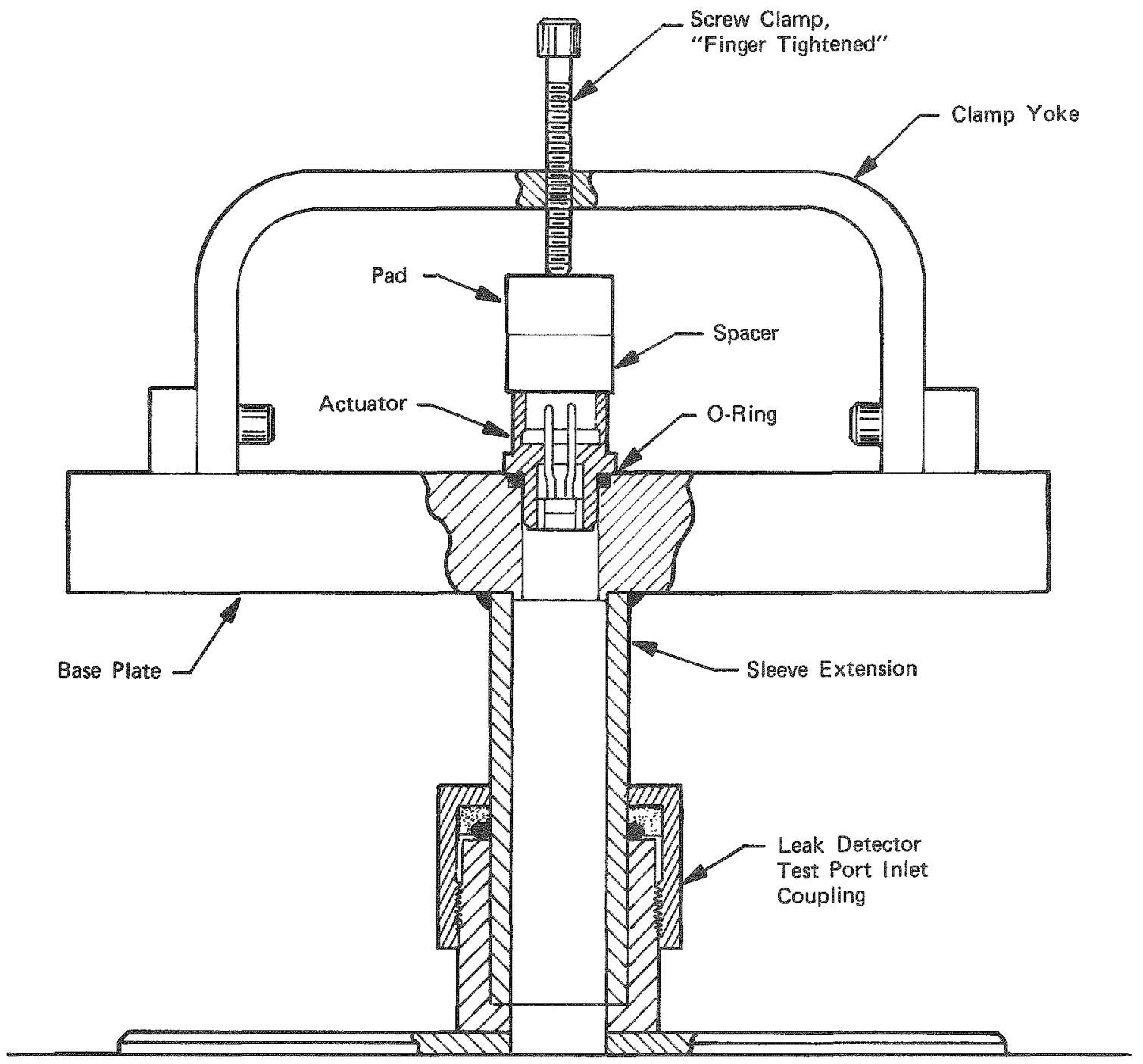

FIGURE 10 - Current leak test fixture.

density and contained as in the present test applications. To guard against possible injury, however, the operators are trained to perform the test in conformance with standard safety practices. various items such as special clothing, etc., used to make the leak test a safe operation, particularly in eliminating static electricity, are illustrated in Figure 12 .

\section{Summary}

A helium bombardment technique was developed to permit leak testing of three nearly identical pyrotechnic actuator devices. The test has been shown to be singularly capable of easily detecting any leakage with a conductance of $1 \times 10^{-7} \mathrm{~cm}^{3}-\mathrm{sec}^{-1}$ or greater. 
Bombardment Testing

1. Equipment
a) Leak Detector:
Airco Temescel, Model LC 40 or equivalent
b) Test Fixture:
Fig. 10, Engr. Dwg. AYD780311 or equivalent
c) Vac/Pressure Chamber:
Fig. 6

2. Sample Preparation
a) Quantity:
Twenty Five or less units per Test
Cycle
b) Pulidown:
Minimum of $20 \mathrm{~min}$ of vacuum $(27 \mathrm{in.}$ Hg or better)
c) Helium Exposure: Minimum of $30 \mathrm{~min}$ (not exceeding $35 \mathrm{~min}$ ) using certified Grade $A$ helium of 5 atmos
3. Sample clean-up: Vacuum (27 in. Hg or better for $5 \mathrm{~min}$, but not exceeding $10 \mathrm{~min}$ )

4. Sample-Measurement
a) Technique:
Single Measurement approach used individ- ually for each sample of test group
b) Data Accessment:
comparison to
specification
c) Identification of leakers:

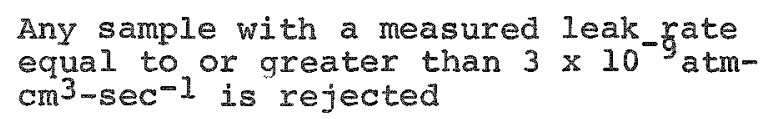

Bubble Testing No longer performed.

\section{References}

1. R. Koftran, E. M. Mielnik and J.S. Ramberg, "Design Evaluation and Implementation of an Automated NonDestructive Leak Test for Integrated Circuit Assemblies," Int. Adv. Nondestr. Test, 5, 327-359 (1977).
2. J. W. Marr, Leakage Testing Handbook, NASA CR - 952, pp 33-39.

3. W. E. Biggs and S. G. Burnett, "Helium Leak Testing: A New Analysis," Electron. Packag. Prod., June 1969. 


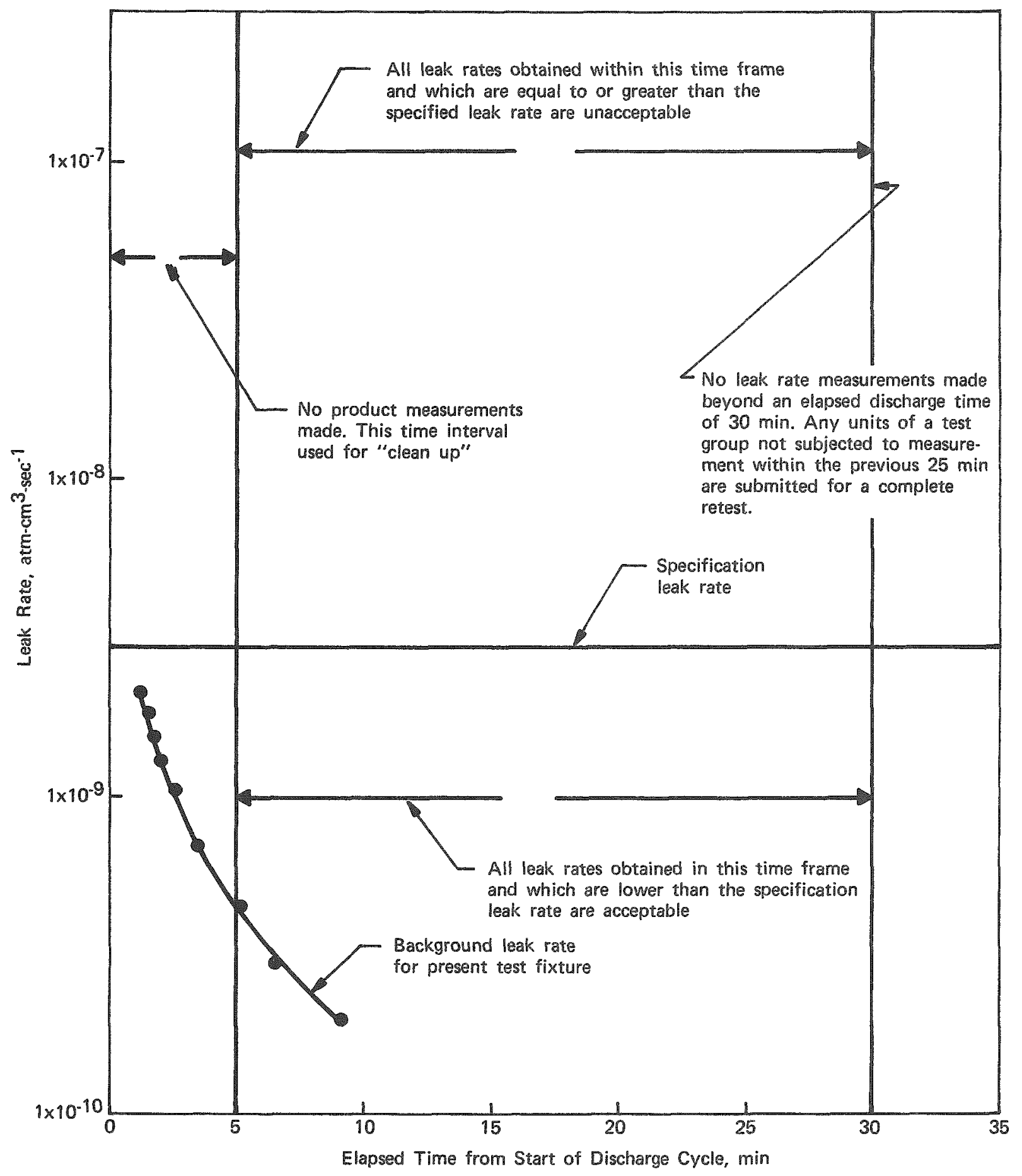

FIGURE 11 - 111Ustration of procedure employed

during the measurement phase of current testing. 


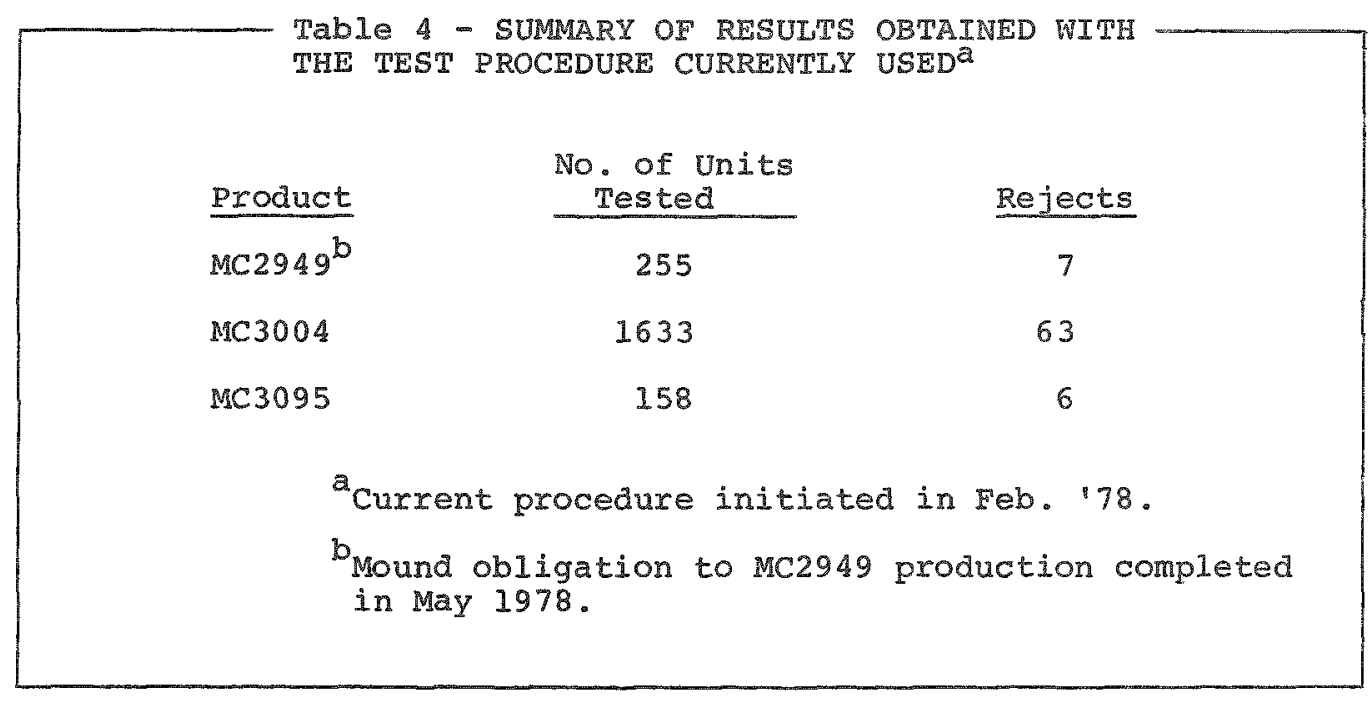

\begin{tabular}{|c|c|}
\hline PROCEDI & PROVIDE OCCASIONAI PROGRAM SUPPORT \\
\hline Products & Purpose of Testing \\
\hline MC2990 & Leak tightness of sleeve component \\
\hline MC3105 & Leak tightness of a filling port seal \\
\hline MC3112 & Leak tightness of closure weld \\
\hline MC3121 & Leak tightness of closure weld \\
\hline
\end{tabular}




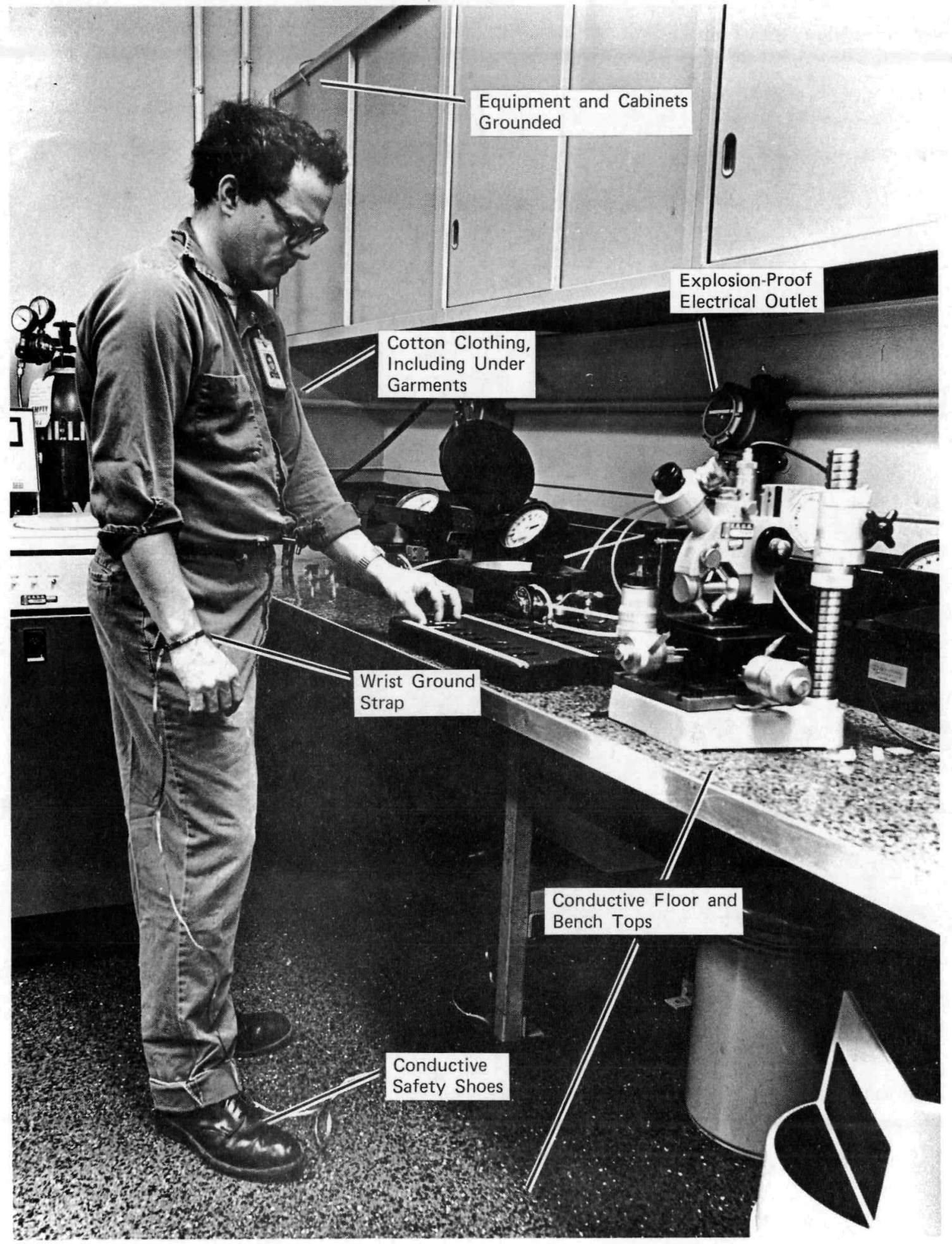

FIGURE 12 - Standard safety precautions. 


\section{Distribution}

\section{EXTERNAL}

H. N Hill, DOE Dayton Area office

R. K. Flitcraft, Monsanto Research Corp.

J.I. Chamberlin, Sandia Laboratories, Albuquerque

J.R. Crain, Sandia Laboratories, Albuquerque

A. K. Jacobson, Sandia Laboratories, Albuquerque

B. R. Steele, Sandia Laboratories, Albuquerque

F. J. Villa, Sandia Laboratories, Albuquerque

A. Stevens, Unidynamics, Phoenix

D. Newsom, Unidynamics, Phoenix

D. Foltz, Unidynamics, Phoenix

\section{INTERNAL}

D. D. Behne

R. T. Braun

W. G. Brotherton

D. J. Brown

J. D. Hastings

T. J. Humanic

C. W. Huntington

R. W. Hurd

D. P. Kel1y

J.R. MCClain

J. G. McGuffee

A. C. Munger

E. E. Tibbetts

T. M. White

V. P. Willson

Publications

Library (10) 